\title{
Tip of the Crime Iceberg
}

\begin{abstract}
We apply the method of expert elicitation to estimate the size of the iceberg and to evaluate reasons why so few white-collar criminals are convicted. We address the following research questions: What is the estimated magnitude of white-collar crime? Why are many white-collar criminals never detected, investigated, prosecuted, and convicted? From our database, we know that 58 white-collar criminals were sentenced to prison every year between 2009 and 2015 in Norway, and we know the average amount involved in their crime. Based on this knowledge, is it possible to estimate the total magnitude of white-collar crime in the country? We recruited a panel of 15 experts to estimate a number of parameters that can determine the total amount of money lost yearly because of white-collar crime.
\end{abstract}

Keywords Categories of crime $\bullet$ Categories of victims $\bullet$ Criminal level - Diversity of participants • Empirical sample • Expert elicitation • Expert judgment inference $\bullet$ Gender $\bullet$ Magnitude of crime $\bullet$ Sources of detection

It is often argued that detected and convicted white-collar criminals only represent the tip of an iceberg in terms of financial crime committed by privileged people in the elite linked to their occupations in society (Langton and Piquero 2007). Ever since Sutherland (1939) coined the term white-collar crime, researchers have studied characteristics of

(C) The Author(s) 2018

P. Gottschalk, L. Gunnesdal, White-Collar Crime in the Shadow Economy, https://doi.org/10.1007/978-3-319-75292-1_3 
white-collar criminals such as their financial motives, their organizational opportunities, and their deviant behaviors. These three dimensions can be integrated into convenience theory as a general explanation of the white-collar crime phenomenon.

However, little is known about the magnitude of white-collar crime.

In this book, we apply the method of expert elicitation to estimate the size of the iceberg and to evaluate reasons why so few white-collar criminals are convicted. We address the following research questions: What is the estimated magnitude of white-collar crime? Why are many white-collar criminals never detected, investigated, prosecuted and convicted?

\section{EMPIRICAL SAMPLE OF CRIMINALS}

From our database, we know that, on average, 58 white-collar criminals were sentenced to prison in Norway every year between 2009 and 2015, and we know the average amount involved in their crime (19 million NOK). The total crime adjusted to 2015 prices thus amounts to 1.137 billion NOK.

Based on this knowledge, is it possible to estimate the total magnitude of white-collar crime in the country? We recruited an expert panel to estimate a number of parameters that could determine the total amount of money lost annually because of white-collar crime. Several estimation approaches were applied in the expert panel: Total dark (i.e., hidden) figure, groups of offenders, groups of offences, groups of victims, gender, and estimates of total crime.

White-collar criminals can be classified into three categories. First, at the top level, we find criminals such as executives and attorneys. Next, at the middle level, we find criminals such as investors and accounting managers. Finally, at the basic level, we find criminals such as accounting clerks and carpenters. In the total sample of 405 convicted white-collar criminals in Norway from 2009 to 2015 , there are 28.4 percent in category 1, 46.1 percent in category 2 and 25.5 percent in category 3 . The amount of money involved in the top level group is much bigger than in group 2, which is again bigger than group 3 (i.e., 33.0 million, 16.6 million and 9.7 million).

Another way of classifying white-collar crime is into crime categories. We make distinctions between four main categories of crime:

- Fraud: The intentional perversion of truth for the purpose of inducing another in reliance upon it to part with some valuable thing belonging to him or to surrender a legal right. Example: False documents to achieve bank financing. 
- Theft: The illegal taking of another person's, group's, or organization's property without the victim's consent. Example: Executive takes corporate art works home.

- Manipulation: The means of gaining illegal control or influence over others' activities, means, and results. Example: Accounting misrepresentation to achieve tax evasion.

- Corruption: The giving, requesting, receiving, or accepting of an improper advantage related to a position, office, or assignment. Example: Procurement executive receives a bribe from a vendor.

In the sample of 405 convicts, 42.6 percent committed fraud, 4.2 percent committed theft, 35.3 percent committed manipulation, and 17.9 percent committed corruption. In cases of fraud, the average amount of money involved is much larger than in the other categories. In fraud cases, the average amount was 25.4 million $\mathrm{NOK}$, in theft cases 4.8 million $\mathrm{NOK}$, in manipulation cases 22.8 million $\mathrm{NOK}$, and in corruption cases 2.5 million NOK.

A third way of classifying white-collar crime is according to categories of victims. We know that 27.9 percent victimized their employers, 22.1 percent victimized the internal revenue service (the Norwegian Tax Administration), 16.4 percent victimized customers, 14.2 percent victimized banks, and 7.4 percent victimized shareholders, while 12.0 percent victimized others. The amount of money involved in crime is larger for bank fraud, insider trading, and tax evasion than for crime against employers, customers, and shareholders. Bank fraud amounts to 49.5 million NOK on average, while insider trading hurting shareholders amounts to 29.8 million NOK, tax evasion 18 million NOK, customer fraud 17.3 million $\mathrm{NOK}$, employee fraud 8.7 million NOK, and others 6.9 million NOK.

A fourth categorization is gender in terms of female versus male criminals. Among the convicts, 7.6 percent were women, while 92.4 percent were men. The average amount of money involved in crime was much larger for male than for female offenders: 20.4 million NOK versus 9.0 million NOK.

These breakdowns in our empirical sample enable experts to indicate a number of probabilities for the iceberg depending on criminal level, criminal type, victim group, and gender. Our ambition as researchers was to apply a number of these breakdowns to arrive at sound estimates from each expert and then accumulate those estimates for all experts. 
In addition to different breakdowns, we also wanted estimates in terms of both an overall and a probability distribution of an estimate of the fraction of white-collar criminals that are caught and brought to justice, in addition to an estimate of the total amount of money involved. Thus, we have a total of seven approaches to estimate the magnitude of white-collar crime:

1. Fraction of white-collar criminals that are caught and brought to justice

2. Fraction with a probability distribution of white-collar criminals that are caught and brought to justice

3. Fraction of white-collar offender groups that are caught and brought to justice

4. Fraction of white-collar crime categories that are detected and lead to conviction

5. Fraction of white-collar crime victim groups that lead to detection and conviction

6. Fraction of white-collar male and female offenders that are caught and brought to justice

7. Total magnitude of white-collar crime in billions of NOK.

We also make distinctions between: (i) white-collar criminals never detected; (ii) white-collar criminals detected, but never investigated; (iii) white collar criminals detected and investigated, but never prosecuted; and (iv) white-collar criminals detected, investigated, and prosecuted, but not sentenced. In all four categories, it is assumed that the offenders are guilty. This research is important in the context of business continuity and risk management, as the iceberg is a threat to business and the number of white-collar criminals never detected is a challenge for risk managers. Furthermore, lack of detection increases the attraction to commit whitecollar crime.

\section{EXPERT ELICITATION}

One approach to estimate the size of the iceberg is the use of expert elicitation. Expert elicitation refers to a systematic approach to synthesize subjective judgments of experts on a topic where there is uncertainty due to lack of data (Heyman and Sailors 2016; Valkenhoef and Tervonen 2016).

The purpose of eliciting and analyzing expert judgment is to use all available information to make expert judgment inference, which is different from statistical inference. Statistical inference means that conclusions 
about the population can be established when the sample is randomly drawn for the population. Expert judgment inference means that experts' estimates represent the state of knowledge. It represents previously unknown and undocumented information. The limited ability to infer does not mean that expert judgments are not valid data. Expert judgments are indeed valid data in that they must be carefully gathered, analyzed, and interpreted (Meyer and Booker 2001). When a number of experts are interviewed, their accumulated guesstimates tend to converge towards numbers that remain stable when more experts are added. Therefore, approximately ten experts from various backgrounds are often sufficient (Heyman and Sailors 2016; Slottje et al. 2008: 7; Valkenhoef and Tervonen 2016).

Expert elicitation seeks to make explicit and utilizable the unpublished knowledge and wisdom in the heads of experts, based on their accumulated experience as well as their interpretation and reflection in a given context. It is a systematic approach that includes expert insights into the subject and also insights into the limitations, strengths, and weaknesses of published studies (Slottje et al. 2008: 7):

Usually the subjective judgment is represented as a 'subjective' probability density function (PDF) reflecting the experts' belief regarding the quantity at hand, but it can also be for instance the experts' beliefs regarding the shape of a given exposure response function. An expert elicitation procedure should be developed in such a way that minimizes biases in subjective judgment and errors related to that in the elicited outcomes.

Meyer and Booker (2001) argue that expert elicitation is invaluable for assessing products, systems, and situations for which measurements or test results are sparse or non-existent. When experts disagree, it can mean that they interpreted the question differently or that they solved it using different lines of thought. Expert judgment can be considered relevant information in the sense that it is data based on qualified opinions. The validity or quality of expert judgment, like any data, can vary. The quality of expert judgment depends on both the completeness of the expert's mental model of the phenomena in question and the process used to elicit, model, analyze, and interpret the data.

In Scandinavia, expert elicitation has been applied to estimate the magnitude of social security fraud. While the estimate for Sweden was 6-7 percent (Delegationen 2008), the estimate for Norway was 5 percent (Proba 2013). Slottje et al. (2008) applied expert elicitation in the Netherlands to assess environmental health impact. 
Expert elicitation faces some of the same challenges as elite interviewing, where there are issues associated with anonymity and confidentiality produced through power relations between researcher and participant (Lancaster 2017). Expert elicitation shares similarities with expert provocation, where critical reflection is stimulated amongst participants on issues that are often otherwise overlooked (Pangrazio 2017).

Through systematic interviews of experts, we tried to estimate the magnitude of white-collar crime in Norway. On our way to a final answer, we were faced with a number of obstacles in our research design. A later chapter explains our research journey by communicating our learning from methodological challenges when applying expert elicitation to estimate the size of an iceberg based on knowledge about the tip of the iceberg. In particular, participation refusals and response confusions are discussed.

\section{EXPERT PANeL}

In expert elicitation, an early methodological step involves identification of experts in the subject area. An expert is anyone especially knowledgeable in the field and at the level of detail being elicited. Meyer and Booker (2001) distinguish between two types of expertise: Substantive and normative. Substantive expertise comes from the expert's experience in the field in question. Normative expertise is knowledge related to the use of the response mode. The response mode is the form in which the expert is asked to give a judgment.

We define experts to be persons who have contributed to detection of white-collar crime. In the sample of 405 convicts, we identified the sources of detection as follows:

- Journalists detected 101 offenders (25 percent).

- Victims detected 52 offenders (13 percent).

- Bankruptcy auditors detected 45 offenders (11 percent).

- Internal auditors detected 45 offenders (11 percent).

- Tax administration employees detected 25 offenders ( 6 percent).

- Bank clerks detected 18 offenders (4 percent).

- External auditors detected 18 offenders (4 percent).

- Police officers detected 9 offenders $(2$ percent).

- Stock exchange employees detected 4 offenders (1 percent).

- Others detected 88 offenders (23 percent). 
It is a diverse range of experts, as recommended by Meyer and Booker (2001), so that the problem of estimating the magnitude is likely to be thoroughly considered from many viewpoints. Diversity of participants is one way to minimize the influence of a single individual. Some of these categories, however, are not relevant or feasible. For example, while a victim of white-collar crime has a strong memory of the episode, there is only one episode, from which the victim as a respondent can hardly generalize.

We developed a questionnaire for the experts and applied the survey in two steps. First, an email was sent to experts informing them about the attached questionnaire and telling them that they would be contacted for a phone interview by a researcher a few days later. During the phone interview, experts had the opportunity to ask the researcher for clarification and discuss issues. While they were talking on the phone, the researcher filled in the questionnaire based on the responses from the expert. The combination of mail and phone as two different communication channels is considered a feasible response mode in line with normative expertise.

We obtained responses in interviews from 15 experts as listed in Table 3.1. On average, the panel reported to have 16 years of experience working with financial crime.

Table 3.1 White-collar crime experts on the elicitation research panel

\begin{tabular}{lc}
\hline Category & Number \\
\hline Investigative journalist in major & 1 \\
newspaper & \\
Experienced bankruptcy attorney & 1 \\
Experienced internal auditor & 1 \\
Tax administration fraud & 3 \\
investigators & \\
Investigative bank manager & 2 \\
Police detective & 1 \\
Corruption researcher & 1 \\
Private fraud examiners & 2 \\
Corporate investor & 1 \\
Defense attorney & 1 \\
Social security fraud investigator & 1 \\
Total respondents & 15 \\
\hline
\end{tabular}


The expert panel listed in Table 3.1 is not perfect, as we would have liked an even closer match to the sources of detection as previously listed. For example, we would have preferred more investigative journalists.

\section{REFERENCES}

Delegationen. (2008). Vad koster felen? Omfattning av felaktiga utbetalingar från trygghetssystemen [What Does the Mistake Cost? Estimation of Wrongful Payments from the Security System]. Stockholm: Delegationen mot felaktiga utbetalningar.

Heyman, J., \& Sailors, J. (2016). A Respondent-Friendly Method of Ranking Long Lists. International Journal of Market Research, 58(5), 693-710.

Lancaster, K. (2017). Confidentiality, Anonymity and Power Relations in Elite Interviewing: Conducting Quality Policy Research in a Politicized Domain. International Journal of Social Research Methodology, 20(1), 93-103.

Langton, L., \& Piquero, N. L. (2007). Can General Strain Theory Explain WhiteCollar Crime? A Preliminary Investigation of the Relationship Between Strain and Select White-Collar Offenses. Journal of Criminal Justice, 35, 1-15.

Meyer, M. A., \& Booker, J. M. (2001). Eliciting and Analyzing Expert Judgment: A Practical Guide, SIAM Books, ASA-SIAM Series on Statistics and Applied Probability. Philadelphia: Society for Industrial and Applied Mathematics (SIAM).

Pangrazio, L. (2017). Exploring Provocation as a Research Method in the Social Sciences. International Journal of Social Research Methodology. Published online https://doi.org/10.1080/13645579.2016.1161346.

Proba. (2013). Trygdesvindel $i$ Norge: En kartlegging av fem stønadsordninger [Social Security Fraud in Norway: A Survey of Five Support Areas]. Oslo: Proba samfunnsanalyse.

Slottje, P., Sluijs, J. P., \& Knol, A. B. (2008). Expert Elicitation: Methodological Suggestions for Its Use in Environmental Health Impact Assessments (RIVM Letter Report). The Netherlands: National Institute for Public Health and the Environment.

Sutherland, E. H. (1939). White-Collar Criminality. American Sociological Review, $5,1-12$.

Valkenhoef, G., \& Tervonen, T. (2016). Entropy-Optimal Weight Constraint Elicitation with Additive Multi-attribute Utility Models. Omega, 64, 1-12. 
Open Access This chapter is licensed under the terms of the Creative Commons Attribution 4.0 International License (http://creativecommons.org/licenses/ by $/ 4.0 /$ ), which permits use, sharing, adaptation, distribution and reproduction in any medium or format, as long as you give appropriate credit to the original author(s) and the source, provide a link to the Creative Commons license and indicate if changes were made.

The images or other third party material in this chapter are included in the chapter's Creative Commons license, unless indicated otherwise in a credit line to the material. If material is not included in the chapter's Creative Commons license and your intended use is not permitted by statutory regulation or exceeds the permitted use, you will need to obtain permission directly from the copyright holder.

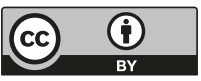

